\title{
Benefícios e riscos da proteção e comercialização da pesquisa acadêmica: uma discussão necessária
}

- Rodrigo Maia de Oliveira*

घéa Velho"*

\section{Resumo}

As práticas de publicação, os sistemas de avaliação e recompensa, a construção das agendas de pesquisa, os mecanismos de proteção e comercialização, a defasagem de infraestrutura e a escassez histórica de recursos humanos qualificados e dedicados ao ensino e à pesquisa são apenas alguns dos inúmeros aspectos que provocam as transformações internas atualmente vividas pela universidade. Este artigo tem como foco principal a análise do impacto do processo de proteção e comercialização dos resultados da pesquisa acadêmica sobre as demais atividades tradicionalmente conduzidas pela universidade. Ainda que a visão mais otimista valorize os impactos positivos dos direitos de propriedade intelectual na academia, não se podem ignorar os eventuais custos ou riscos envolvidos nesse processo. Por fim, o artigo sugere novos estudos que podem contribuir para o acompanhamento e avaliação das universidades brasileiras e para a elaboração de politicas de Ciência e Tecnologia e de Educação Superior.

Palavras-chave: Universidade. Propriedade intelectual. Patentes. Revolução acadêmica.

\section{Benefits and risks of protection and commercialization of academic research: an essential discussion Abstract}

The research university worldwide has been undergoing considerable internal transformation. The reasons are manifold ranging from changes in publishing behaviour triggered by evaluation and research systems, to social and government pressure on the set up of research agendas, to the difficulty in maintaining adequate infrastructure and qualified human resources up to the newly created mechanisms for protection and commercialization of research results. The latter is the focus of this article, which analyses the diverse and conflicting views of the impact of the patenting and licensing process (IPRs) of

Doutorando junto ao Departamento de Politica Científica e Tecnológica do Instituto de Geociências da UNICAMP. E-mail:maia@ige.unicamp.br

“* Professora Titular do Departamento de Política Científica e Tecnológica do Instituto de Geociências da UNICAMP.

E-mail:velho@ige.unicamp.br 
academic research results on the traditional activities carried out by universities, namely research and teaching. It argues that the benefits of IPRs must be weighted against the risks involved in this process. The article suggests questions and approaches for new studies that could contribute to monitor and assess Brazilian universities and to design Science and Technology and Higher Education policies.

Keywords: University. Intellectual property. Patents. Academic revolution.

\section{Beneficios y riesgos de la protección $y$ comercialización de la investigación académica: una discusión necesaria Resumen}

Las prácticas de publicación, los sistemas de evaluación y recompensa, la construcción de las agendas de investigación, los mecanismos de protección y comercialización, lo atraso de la infraestructura y la escasez histórica de los recursos humanos calificados y dedicados (entregados) a la enseñanza y a la investigación son apenas algunos de los innúmeros aspectos que provocan las transformaciones internas vividas recientemente por la universidad. Este artículo tiene como enfoque principal el análisis del impacto del proceso de protección y comercialización de los resultados de la investigación académica a cerca de las actividades tradicionalmente conducidas por la universidad. Aunque la visión optimista valore los impactos positivos de los derechos de la propiedad intelectual en el medio académico, no se debe ignorar los costos o riesgos envueltos en ese proceso. La universidad, como parte interesada en mantener los beneficios y disminuir los riesgos, debe focalizar los procesos de transformación interna, principalmente los que puedan producir efectos directamente en sus objetivos. Al final, el artículo sugiere nuevos estudios que contribuyan para el acompañamiento y evaluación de las universidades brasileñas y para la elaboración de políticas de Ciencia y Tecnología y de Educación Superior.

Palabras clave: Universidad. Propiedad intelectual. Patentes. Revolución académica.

\section{Introdução}

A Universidade atual encontra-se inserida em um ambiente caracterizado por mudanças organizacionais, por modificações no comportamento dos principais atores envolvidos com o desenvolvimento econômico e social e pela expectativa de que ela se envolva em novos arranjos interinstitucionais que resultem em beneficios baseados em conhecimento científico e tecnológico e na inovação. A partir desse contexto, alguns pesquisadores têm argumentado que a universidade vive um processo de transformação no que diz respeito às suas funções sociais ligadas à produção e transferência de conhecimento para a sociedade (WEBSTER, 1990; WEBSTER; ETZKOWITZ, 1998; 
GIBBONS et al., 1994; ETZKOWITZ; LEYDESDORFF, 1996, 2000; BRISOLLA, 1998b; ZIMAN, 1999; MARTIN; ETZKOWITZ, 2000; METLAY, 2006).

Dentre as várias possibilidades de dispor o conhecimento acadêmico à sociedade, a transferência de tecnologia tem alcançado significativo destaque, principalmente por meio da execução de projetos de pesquisa e desenvolvimento (P\&D) cooperativos entre universidades e empresas. Em consequência disso, mais recentemente, observa-se uma crescente valorização do uso do sistema de propriedade intelectual (PI) como mecanismo de regulação desse processo colaborativo, sendo a patente a sua forma mais conhecida.

Embora seja razoavelmente consensual a idéia bastante otimista de que os direitos de propriedade intelectual (PI) podem ter, potencialmente, impactos positivos quando explorados pelas universidades, alguns poucos autores têm chamado a atenção para o fato de que a maior parte da literatura se refere a essas vantagens sem levar em conta os custos ou riscos envolvidos nessas atividades. Além disso, as mesmas vantagens são apresentadas sem qualquer evidência empírica com suporte estatístico e, por isso, podem ser consideradas, no estado atual do conhecimento da questão, apenas como hipóteses (GEUNA; NESTA, 2004, 2006).

Tomando como referência a literatura acadêmica relevante ao tema, este artigo tem o objetivo de discutir as posições apresentadas pelos diversos autores a respeito das tão propaladas transformações internas vividas pela Universidade, que são impulsionadas por uma série de fatores. As práticas de publicação nas diversas áreas do conhecimento têm se alterado profundamente em função dos sistemas de avaliação e recompensa baseados cada vez mais em bases e práticas internacionais (VELHO, 2008). Estes novos parâmetros de avaliação têm impacto na construção das agendas de pesquisa da universidade, levando os pesquisadores, por um lado, a se concentrarem em problemas que sejam "publicáveis" em nível internacional. Por outro lado, a política de Ciência e Tecnologia (C\&T) e de ensino superior sinaliza, através da criação de mecanismos de proteção e comercialização da pesquisa universitária, a importância da aproximação da universidade com o setor produtivo e, portanto, da pesquisa mais aplicada. Embora se reconheça que essas transformações ocorrem em inúmeros aspectos que permeiam o ambiente acadêmico, é impossivel analisá-las todas em um mesmo artigo. Assim, o foco principal aqui se dá no impacto do processo de proteção e comercialização dos resultados da pesquisa conduzida pela universidade sobre as demais atividades acadêmicas. Esta análise é relevante porque tem sido apontado que o incentivo a práticas proprietárias pelas universidades (particularmente as públicas) afeta (negativamente, para alguns, e positivamente, para outros autores) o desempenho das funções precípuas da universidade, quais sejam, a qualidade do ensino, a formação de recursos humanos e a produção de conhecimento público. 
0 artigo está estruturado em três partes principais, além desta introdução. A seção 1 apresenta os argumentos e modelos que alimentam a tese de que a universidade vive um processo de transformação interna, abordando os principais posicionamentos e justificativas dos autores que veem essa transformação como benéfica e daqueles que a consideram como prejudicial para as funções e atividades que a universidade deve cumprir. A seção 2 destaca o processo de proteção e comercialização da pesquisa acadêmica como um dos aspectos de análise do processo de transformação interna da universidade. 0 artigo se encerra sugerindo que a universidade, como parte interessada, deve dedicar atenção especial ao processo de proteção e comercialização da sua pesquisa que tem sido estimulado pelas políticas recentes. Sugere, também, direções de pesquisa importantes para que se possa entender com mais clareza a natureza e os impactos da privatização do conhecimento produzido pelas universidades públicas brasileiras.

\section{A proteção e comercialização da pesquisa acadêmica}

0 papel que a universidade assume na sociedade vem sendo objeto de inúmeras pesquisas há várias décadas. No entanto, o contexto atual da economia mundial oferece novas possibilidades de abordagem do tema. 0 encurtamento do ciclo de inovação tecnológica e a crescente incorporação dos conhecimentos científicos na base do progresso técnico têm valorizado o papel da universidade no que se refere à sua função social ligada à produção e transferência do conhecimento para a sociedade.

$\mathrm{Na}$ academia, o tema tem sido tratado por dezenas de pesquisadores de diversas nacionalidades, que adotam diferentes perspectivas para apresentar suas reflexões, filiações teóricas, metodologias, resultados e conclusões em seus trabalhos científicos. Obviamente, por conta dessa diversidade, além da enorme variedade de universidades que existem no mundo, e dos diferentes contextos em que se inserem tais universidades, os trabalhos trazem argumentos que não seguem, necessariamente, uma sistemática que permita uma análise direta e objetiva e, muito menos, conclusões gerais sobre os ganhos e problemas advindos desta aproximação entre universidades e setor produtivo. Assim, este artigo se propõe a discutir os argumentos apresentados pelos diversos autores a respeito das possiveis transformações internas vividas pela universidade, contribuindo para o esboço de um arcabouço teórico que sustente a análise do processo de proteção e comercialização da pesquisa acadêmica. Essa proposta passa pela percepção de que é possivel estruturar de maneira coerente os diferentes posicionamentos relacionados ao tema (DAVID; HALL, 2006).

Por fim, faz-se necessário esclarecer que não houve a preocupação de promover uma análise predominantemente histórica, que seguisse uma escala de tempo determinada. Ao invés disso, optou-se por apresentar os diversos pensamentos e argumentos, relacionando-os de maneira que eles pudessem "conversar entre si". 


\section{O processo de transformação (revolução) acadêmica}

Considerando que as teses acadêmicas venham sempre acompanhadas do olhar particular de cada pesquisador ou grupo de pesquisadores, apresentam-se nesta seção alguns argumentos discutidos na literatura sobre a universidade, na tentativa de melhor entender sua natureza e seu comportamento enquanto instituição geradora e disseminadora de conhecimento.

Vale dizer que a pesquisa acadêmica sobre a universidade não é uma atividade trivial ou simples. A complexidade dessa tarefa reside na compreensão de que existem diferentes tipos de universidade, ou ainda "espécies" como Martin e Etzkowitz (2000) preferem dizer. Existem também, claro, diferentes paises em que elas se inserem. Para alguns destes paises, sem dúvida, os problemas relativos à defasagem de infraestrutura e à escassez histórica de recursos humanos qualificados e dedicados ao ensino e à pesquisa podem ser mais importantes para as transformações internas atualmente vividas pela universidade do que 0 próprio processo de comercialização dos resultados da pesquisa'. Além disso, para aqueles que se propõem a buscar indícios que corroborem suas teses, cabe a escolha de um período de tempo sobre o qual a observação deverá ocorrer. Por fim, ainda sobre 0 processo de análise, também deve haver alguma habilidade do pesquisador na escolha de quais aspectos ou comportamentos servirão de objeto de observação para comprovar a mudança ou a manutenção do status quo. Mesmo reconhecendo esta enorme diversidade da "espécie" Universidade, para que se possa fazer a análise aqui proposta é necessário que se pense em uma 'universidade típica de pesquisa', sem se precisar muito sua definição e contando com o conhecimento tácito de cada leitor sobre o que isso significa.

Dessa forma, considerando as normas Mertonianas² da ciência, Metlay (2006) afirma que desde a primeira metade da década de 70, a academia tem vivido um período que ele chama de "renormalização". Neste, destaca-se o deslocamento da norma do "comunismo" - segundo a qual o pesquisador se torna obrigado a divulgar seus resultados de pesquisa que são vistos como produtos de uma colaboração social sendo, portanto, "bem comum" - pela norma da "propriedade intelectual".

Ainda na década de 70, Mulkay (1979) foi categórico em criticar a perspectiva ortodoxa que se baseia nos chamados princípios normativos gerais da ciência (MERTON, 1970). Para tanto, ele apresenta duas razões principais pelas quais essa estrutura normativa da ciência é insatisfatória para entender como o conhecimento científico se estabelece. A primeira delas sugere que, de fato, apenas parte desses princípios normativos ocupa um papel significativo na prática da ciência. $A$ segunda razão indica que tanto os princípios gerais quanto as normas operacionais mais especificas devem ser interpretadas para cada contexto particular.

\footnotetext{
Essa ideia foi sugerida pelo parecerista.

2 De acordo com Merton (1970), a ciência acadêmica segue um conjunto de normas sociais implícitas, que conformam o que ele denomina como " ethos científico" ou "Cudos", sendo esta última denominação um acrônimo dos termos: Comunalism (Comunalismo), Universalism (Universalismo), Disinterestedness (Desinteresse) e Organized Skepticism (Ceticismo Organizado).
} 
Mulkay (1979) sugere ainda que as normas da ciência devem ser tratadas como um "conjunto de palavras"3 que são empregadas pelos membros dessa comunidade (cientistas) na negociação dos significados das suas próprias ações e nas ações dos seus colegas acadêmicos. Dessa forma, segundo o autor, a adoção de uma determinada interpretação em detrimento de outra pelos cientistas é resultado de um processo de interação social e de negociação no qual as visões de cada um deles ou do grupo podem ser modificadas, abandonadas ou reforçadas.

No entanto, segundo Metlay (2006), é impossivel estudar a universidade moderna (a universidade de pesquisa) sem considerar que a prática científica e a academia estão submetidas a uma mudança radical em direção à comercialização da sua pesquisa. $\mathrm{A}$ literatura acadêmica sobre a universidade moderna evidencia esse sentido de "renovação" (com conotação positiva) em uma série de formas implícitas e explícitas. A defesa mais clara dessa condição de modernidade aparece nos trabalhos de Henry Etzkowitz e outros sociólogos da ciência com afinidade às tradições Mertonianas (METLAY, 2006).

Em um trabalho publicado em 1991, Webster e Etzkowitz afirmam haver duas visões distintas entre aqueles que exploram o processo de renovação na universidade. Na primeira visão prevalece o argumento de que a universidade vive uma extensão de modelos antigos e que o seu papel funcional e a natureza do seu relacionamento com outras instituições não têm sido alterados dramaticamente. A segunda visão sugere que existem mudanças quantitativas e estruturais anunciando o surgimento de um novo tipo de instituição acadêmica, orientada muito mais diretamente a executar um papel em nome do Estado como uma agência de desenvolvimento econômico (WEBSTER; ETZKOWITZ, 1991).

Filiados a essa segunda visão, Webster e Etzkowitz (1991) propõem, por meio de trabaIhos conduzidos e publicados ainda no final dos anos 80 e início dos anos 90, a idéia de que se encontra em processo uma "Segunda Revolução Acadêmica". ${ }^{4}$ Tal idéia se desenvolve com base no argumento de que têm havido importantes modificações de tendências com respeito à comercialização da pesquisa acadêmica e mudanças que afetam os relacionamentos que acontecem dentro da universidade e entre academia e indústria. Os autores vão além, afirmando que o que se observa é o início de um novo "contrato social" entre academia e sociedade, sendo o apoio financeiro oferecido pelo Estado para a pesquisa acadêmica mantido apenas quando e enquanto a pesquisa executar um papel chave na nova economia.

$\mathrm{Na}$ suposição de que esse novo contrato social seja honrado, Webster (1990) acredita que, no auge do progresso dessa Segunda Revolução Acadêmica, sejam fundadas novas estruturas transacionais hibridas que combinem atividades de P\&D acadêmicas e industriais.

\footnotetext{
${ }^{3}$ No texto original Mulkay (1979) usa, mais precisamente, a expressão "vocabulário".

${ }^{4}$ Segundo esses autores (WEBSTER; ETZKOWITZ, 1991), a Primeira Revolução Acadêmica se deu no século XIX quando a atividade de pesquisa deixou de ser, em grande parte, uma atividade individual praticada nas casas ou laboratórios particulares dos cientistas e foi institucionalizada, levada para dentro da universidade, tornando-se uma atividade profissional adicional ao ensino. A Universidade de Berlim representa o marco do rompimento com o padrão anterior de universidade.
} 
Para alguns autores (BRISOLLA, 1998b) esse novo contrato social já apresentava, antes mesmo do final da década de 90, novos desafios para a legitimação da pesquisa acadêmica. A National Science Foundation (NSF) - principal órgão governamental norte-americano de financiamento da pesquisa básica - vem seguindo determinações políticas que exigem, com base num decreto-lei norte- americano de 1993, que as agências de financiamento à pesquisa destinem 2/3 de seus recursos para pesquisas com perspectiva de impacto socioeconômico.

No Brasil, o enfoque desse novo contrato social também pode ser encontrado em alguns programas governamentais, conduzidos geralmente pelas agências de fomento, tal como o Conselho Nacional de Desenvolvimento Científico e Tecnológico (CNPq). Para ilustrar esse enfoque, segue destacado um breve trecho da parte inicial do relatório anual de atividades do CNPq em 2001, ano marcado pela celebração dos seus 50 anos.

Além disso, a política de fomento implementada pelo CNPq permite hoje agregar aos históricos critérios de excelência de pesquisadores e centros de pesquisa os critérios de relevância pelos quais se contemplam os grandes temas que emergem da realidade social e produtiva brasileira.

De um modelo voltado quase exclusivamente para o atendimento da demanda espontânea, o sistema de apoio à pesquisa evolui, fazendo com que o CNPq passe a operar também segundo um modelo que, apoiado nos programas como fortes instrumentos da ação, enfatiza questões cujas soluções são cruciais para que o país logre alcançar seu desenvolvimento com justiça e equidade social. (BRASIL, 2001).

No entanto, acredita-se que as mudanças não ocorrem somente no nível institucional e atingem o indivíduo que participa ativamente do sistema. Para Etzkowitz e Webster (1994), existe uma mudança no comportamento do pesquisador acadêmico que trabalha na universidade atual. Para os autores, o sucesso do trabalho do pesquisador acadêmico depende da sua adesão, enquanto cientista, a uma lógica de trabalho que funciona de acordo com um modelo multidirecional no qual soluções práticas geram questões de pesquisa básica e vice-versa. Consequentemente, as normas da ciência também se alterariam no sentido de acomodar o modelo de pesquisa multidirecional e o apoio oferecido pelas empresas.

0 surgimento do ethos comercial dentro do ambiente acadêmico e a emergência de conflitos sobre esse desenvolvimento culminam em uma mudança normativa na ciência (ETZKOWITZ, 1998). Dentro dessa concepção de mudança, a "difusão do conhecimento", um valor tradicional arraigado ao comportamento acadêmico, passa a apresentar uma relação de compatibilidade com o conceito da "capitalização do co- 
nhecimento". Dessa forma, a norma da ciência que tradicionalmente condena a motivação do pesquisador pelo resultado financeiro ${ }^{5}$ - a norma do desinteresse proposta por Merton (1970) - está sendo modificada de forma a permitir o desenvolvimento de um tipo de ciência empreendedora. Essa transição estaria ocorrendo a partir de oportunidades cognitivas, de rearranjos institucionais e de uma mudança normativa que, por sua vez, tem efeitos cognitivos sobre a agenda de pesquisa futura.

Esse novo modelo de pesquisa multidirecional, conhecido como Modelo da Hélice Tripla (Triple Helix), começou a ser discutido a partir de uma proposta feita por Etzkowitz e Leydesdorff (1996) e continua sendo alvo de uma série de conferências internacionais. A primeira delas, realizada em janeiro de 1996, na cidade de Amsterdã, na Holanda, reuniu um grupo de 80 pesquisadores e analistas políticos de 30 diferentes paises. Atualmente na sua sexta versão, ocorrida em Cingapura, em 2007, a conferência já acumula passagem por vários paises, tais como: EUA (Nova lorque), Brasil (Rio de Janeiro), Dinamarca (Copenhagen), Suécia (Lund) e Itália (Turim).

Etzkowitz e Leydesdorff (2000) argumentam que há quem prefira rotular com diferentes nomes os diversos modelos que, historicamente, apareceram para representar as relações entre universidade-indústria-governo (versões I, II e III da Hélice Tripla).

$\mathrm{Na}$ primeira versão, o Estado (governo) aparece com ator central que cerca a universidade e a indústria e dirige as relações estabelecidas entre eles (figura 1).

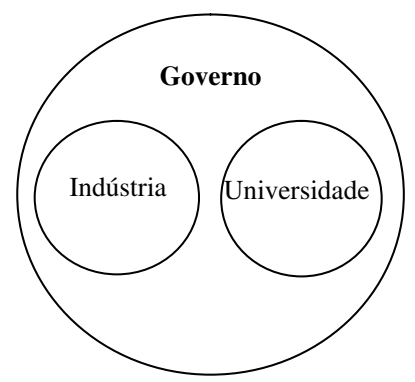

Figura 1 - Um modelo estático das relações universidade-indústria-governo. Fonte: Etzkowitz e Leydesdorff (2000).

Os exemplos mais fortes usados para ilustrar essa configuração, onde há uma significativa presença do Estado, podiam ser encontrados em países como a antiga União Soviética e alguns paises do Leste Europeu, onde, durante várias décadas, prevaleceu o regime socialista. Configurações mais amenas desse modelo seriam facilmente encontradas em paises latino-americanos e alguns paises europeus tais como a Noruega (ETZKOWITZ; LEYDESDORFF, 2000).

5 Para ser mais preciso, o autor usa a expressão "profit-making". 
No entanto, a Hélice Tripla I é vista como um modelo de desenvolvimento falho, com poucas possibilidades para as iniciativas bottom up ${ }^{6}$, e onde a inovação foi mais desencorajada do que estimulada. Usando alguns casos especificos ocorridos na América Latina, Sutz (2000) afirma que, com raras exceções, os resultados dos mecanismos top-down ficaram bem abaixo das expectativas dos politicos de C\&T (policy makers), na medida em que não houve melhoria significativa no baixo envolvimento histórico da indústria com atividades de conhecimento e de inovação tecnológica.

Ainda de acordo com a autora (SUTZ, 2000), alguns aspectos que conformavam o contexto latino-americano do final do século XX ajudam a explicar tais resultados insatisfatórios, sendo eles: (i) o drástico emagrecimento do Estado seguido pelo processo de privatização e internacionalização do processo de geração e acúmulo de conhecimento; (ii) a inserção "periférica" da América Latina na economia mundial, mantendo o padrão histórico da troca de bens e serviços com baixo conteúdo tecnológico por outros com alto conteúdo tecnológico; (iii) a manutenção da tradição da Universidad de la Reforma impregnada de desconfiança e repugnância sobre as relações entre universidades públicas, indústria e governo; (iv) a elevada desigualdade socioeconômica dificultando significativamente a melhoria das capacidades técnicoprodutivas; e (v) a fragilidade dos Sistemas Nacionais de Inovação Latino-Americanos, devido principalmente à negligência histórica da inovação técnica.

Um segundo modelo, o da Hélice Tripla II, é formado por esferas institucionais separadas por limites explícitos e com relações altamente circunscritas entre as esferas (figura 2). Essa segunda versão vincula-se à política de mercado, defendida como sendo uma "terapia de choque" para reduzir o papel do Estado tão presente na primeira versão.

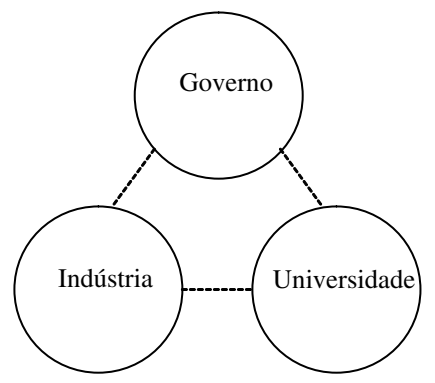

Figura 2 - 0 modelo de "livre mercado" para as relações universidade-indústria-governo. Fonte: Etzkowitz e Leydesdorff (2000).

\footnotetext{
${ }^{6}$ Sutz (2000) apresenta as duas diferentes abordagens, bottom-up e top-down, com foco sobre as relações universidadeindústria-governo, no contexto latino-americano. Na abordagem bottom-up, a análise ocorre sobre as experiências concretas de relações de conhecimento entre usuário-produtor. Na abordagem top-down a análise recai sobre os resultados dos esforços de institucionalização das relações universidade-indústria-governo, com foco no papel de cada ator.
} 
Um modelo semelhante, surgido na América Latina e denominado como Triângulo de Sábato, foi apresentado em 1968 por Jorge Sábato (na época, diretor da Comissão Nacional de Energia Atômica da Argentina) e Natalino Botana (na época, pesquisador do Instituto para a Integração da América Latina). Eles propuseram, para a superação do subdesenvolvimento da região e o seu acesso à condição de sociedade moderna, a realização de uma ação decisiva no campo da pesquisa científico-tecnológica.

Os argumentos expostos por Sábato e Botana (1968) compreendiam: a maior eficiência na absorção de tecnologias, a existência no país receptor de uma sólida infraestrutura científico-tecnológica; o reconhecimento da especificidade das condições de cada país para conseguir uma utilização inteligente dos fatores de produção; a necessidade de exportar bens com maior valor agregado e o fato de que ciência e tecnologia são catalisadores da mudança social.

Baseados em estudos prospectivos com o horizonte do ano 2000, Sábato e Botana (1968) advogavam que a região podia e devia participar no desenvolvimento científico e tecnológico. A partir da compreensão acerca do processo político de desenvolvimento nas sociedades contemporâneas, recomendaram eles, como estratégia para que essa participação fosse possivel, a inserção da ciência e da tecnologia na própria trama do processo de desenvolvimento. Isso resultaria da ação múltipla e coordenada de três elementos fundamentais para o desenvolvimento das sociedades contemporâneas: o governo, a estrutura produtiva e a infraestrutura científico-tecnológica.

Essa configuração foi descrita por meio de um triângulo, cujo vértice superior é ocupado pelo governo, enquanto os outros dois elementos ocupam os vértices da base na qual o triângulo está apoiado. Plonski (1995) descreve os três tipos de relações que ocorrem no "Triângulo de Sábato": intra-relações, são aquelas que ocorrem entre os componentes de um mesmo vértice; inter-relações, que são as que se estabelecem deliberadamente entre pares de vértices; e extrarrelações, que são as que se criam entre uma sociedade e o exterior, manifestando-se, por exemplo, no intercâmbio científico, no comércio externo de tecnologia e na adaptação de tecnologias importadas.

Ainda segundo Plonski (1995), o Triângulo de Sábato veio, com o avanço do tempo, sofrendo evoluções para modelos mais complexos. A indicação dessa evolução aparece com o modelo do Tetraedro de Petrillo, apresentado pelo Professor Jorge Domingo Petrillo (na época, reitor da Universidade Nacional de Mar del Plata, na Argentina). Esse novo modelo geométrico incorpora um novo vértice, devido à inclusão do setor financeiro como sendo um agente relevante no processo.

Algumas críticas podem ser feitas ao modelo do tetraedro no que se refere à suposição de que o novo agente proposto já está presente no Triângulo de Sábato, mas sem possuir uma delimitação que lhe desse forma, através das agências de 
fomento, das organizações de apoio internacional (através do estabelecimento das extrarrelações) e do próprio governo como responsável pelo aporte financeiro disponivel ao processo de investimento em C\&T envolvido nas intra-relações.

Na verdade, a idéia da inclusão de novos vértices sugere a crescente busca dos analistas da questão pelo detalhamento e aprimoramento de modelos pré-definidos. Essa parece ser uma consequência natural do processo de evolução conceitual dos modelos, sendo os mais antigos aperfeiçoados em busca de uma nova abordagem que explique melhor o fenômeno estudado.

Em suma, as versões I e II da Hélice Tripla demonstram uma preocupação com a configuração estática desses modelos. A versão III procura avançar além dessa linha de pensamento, incluindo novos elementos nos vértices da representação geométrica, com ênfase adicional para a dinâmica do modelo.

Assim, a Hélice Tripla III baseia-se em uma infraestrutura de conhecimento representada por esferas institucionais superpostas, com cada uma delas executando o seu papel e também parte das ações das demais, com organizações hibridas surgindo das interfaces (figura 3). A área superposta pelas três esferas, que aparece destacada na figura 3.a, representa a região onde se encontram as cadeias tri-laterais e as organizações hibridas.

a)

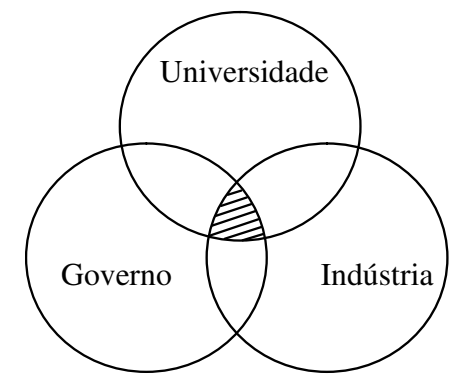

b)

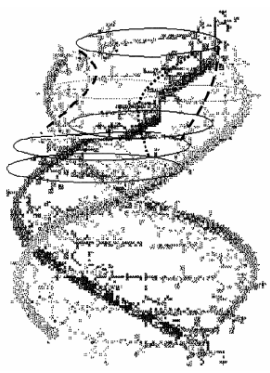

Figura 3 - a) Representação bidimensional da Hélice Tripla (versão III), indicando o espaço das relações universidade-indústria-governo e b) Representação da Hélice Tripla (versão III), indicando a superposição das comunicações e a reconstrução dos arranjos institucionais.

Fonte: Etzkowitz e Leydesdorff (2000).

De acordo com Etzkowitz e Leydesdorff (2000), as diferenças entre as duas primeiras versões (I e II) e o último arranjo da Hélice Tripla (III) apresentam um caráter de interesse normativo. Tanto no caso da primeira como na segunda versão, a maioria dos paises e regiões está tentando atingir alguma forma da terceira versão da Hélice Tripla, com o objetivo de elaborar um ambiente inovativo constituído por spin-offs universitários; por iniciativas trilaterais para o desenvolvimento econômico baseado no conhecimento e por alianças estratégicas entre empresas (grandes 
e pequenas, operando em diferentes áreas e com diferentes niveis de tecnologia), laboratórios governamentais e grupos de pesquisa acadêmicos. Tais arranjos são frequentemente encorajados, mas não controlados, pelo governo através de novas "regras", pelo auxílio financeiro direto ou indireto ou por meio de novos organismos promotores da inovação.

Embora no Brasil o modelo da Hélice Tripla seja aceito com significativa amplitude, seu desenvolvimento não ocorre na ausência de um posicionamento crítico. De acordo com Dagnino (2003, p. 270), a construção do modelo tem como elemento indutor

proposições que funcionam ao mesmo tempo como direções de pesquisa da realidade observada, como imagens de futuro tendencialmente projetados pelos atores envolvidos em função do resultado esperado de suas ações, da idealização de processos que julgam ter ocorrido em outras latitudes e, também, como conclusões provisórias que orientam a formulação de recomendações politicas.

Filiado ao "Pensamento Latino-Americano em Ciência, Tecnologia e Sociedade", Dagnino (2003) defende que o fortalecimento da relação UniversidadeEmpresa (U-E) deveria passar, necessariamente, por transformações estruturais nos níveis social, econômico e político e pela introdução do tema na agenda do processo de tomada de decisão da comunidade de pesquisa e dos policy makers. Além disso, o autor indica haver algum consenso de que o interesse das empresas sobre os resultados da pesquisa universitária não deve sobrepujar os resultados a serem obtidos pela qualidade dos recursos humanos formados por elas e contratados pelas empresas.

Outra abordagem que corrobora a existência de um processo de transformação acadêmica é proposta por Gibbons e outros (1994). Segundo os autores, vivemos um "processo de mudança" do "Modo 1" para o "Modo 2" de produção de conhecimento. 0 Modo 1 seria caracterizado pela produção isolada do conhecimento por universidades e outras instituições acadêmicas, realizada com pouco ou quase nenhum envolvimento com as necessidades sociais, sendo os resultados das pesquisas transferidos diretamente para seus usuários finais.

A descrição do Modo 1, proposto por Gibbons e outros (1994), remete imediatamente ao conceito do Modelo Linear de Inovação, conhecido por servir de base ao pensamento do processo de inovação e da política científica e tecnológica, inicialmente nos paises desenvolvidos e mais tarde nos paises em desenvolvimento. 0 referido modelo tinha (ou ainda tem) como pressupostos principais: a correspon-

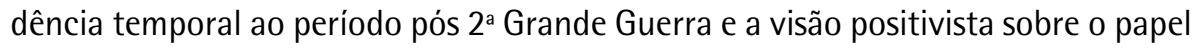


da ciência e da tecnologia para o progresso apresentada pelo Relatório Vannevar Bush $^{7}$. Dentro dessa visão positivista, estavam incluidas:

- a ênfase na pesquisa básica como motor de desenvolvimento da ciência, tecnologia e inovação;

- a existência de uma sequência unidirecional de eventos (pesquisa básica, pesquisa aplicada, desenvolvimento, inovação e difusão) separados cronologicamente, sem a possibilidade de retroalimentações e;

- a clara separação ou especialização institucional na qual determinadas instituições executariam suas atividades isoladamente.

0 Modelo Linear de Inovação passou a ser amplamente criticado a partir da década de 80, quando aparecem os textos de Kline e Rosenberg (1986) com proposições de reformulação ao relacionamento entre ciência e tecnologia.

No Modo 2, proposto por Gibbons e outros (1994), em contraste ao Modo 1, a atividade de produção do conhecimento seria caracterizada pela multi e transdisciplinaridade, sendo conduzida simultaneamente por uma crescente variedade de instituições, de diversas naturezas. Nesse arranjo haveria um desmantelamento dos limites institucionais, sendo o conhecimento produzido no contexto da sua aplicação, com influência direta da sociedade.

0 Modo 2, proposto por Gibbons e outros (1994), encontra similaridade ao Modelo Interativo de Inovação apresentado por Kline e Rosenberg (1986) e caracterizado pelos seguintes aspectos:

- a transferência do papel central do processo de inovação, que no Modelo Linear de Inovação recaía sobre a atividade de pesquisa básica, para a empresa;

- dentro da empresa, as atividades de projeto ocupam o papel central no processo de inovação, obviamente orientado pelas diretrizes de mercado;

- como as empresas não estão isoladas, é preciso considerar que o processo de inovação interativo se estabeleça a partir de dois tipos de relações básicas distintas e complementares que são:

- aquelas que se estabelecem dentro da própria empresa ou entre empresas do mesmo setor (matrizes e subsidiárias ou entre clientes e fornecedores);

${ }_{7}$ Relatório enviado ao Sr. Franklin D. Roosevelt, Presidente dos Estados Unidos, elaborado pelo então diretor do Escritório de Pesquisa Científica e Desenvolvimento, Sr. Vannervar Bush, em julho de 1945. 
- aquelas que se estabelecem entre a empresa e o sistema de Ciência e Tecnologia (C氏tT), entendido como duas instâncias distintas, sendo uma delas o "estoque" de conhecimento e a outra a atividade de pesquisa; e

- a consideração de que essas relações não são únicas e nem lineares (unidirecionais), ou seja, elas são variadas e multidirecionais, coloca em destaque o papel das retroalimentações dessas relações dentro do modelo interativo.

Dessa forma, é natural supor que se busque definir em que Modo (1 ou 2) de produção de conhecimento a sociedade atual se encontra. No entanto, Martin e Etzkowitz (2000) sugerem que ao invés de tentar identificar evidências claras de que o conhecimento seja hoje produzido de acordo com os Modos 1 ou 2, talvez seja mais proveitoso pensar que a sociedade atual se encontra em uma posição intermediária, que contém evidências dos dois "Modos".

A literatura apresentada acima resume os principais argumentos que se relacionam com a tese da existência ou não de um processo de transformação que estaria ocorrendo dentro da universidade atual. Ainda que as percepções e argumentos dos vários autores se manifestem por meio de diferentes modelos, parece haver um grau razoável de consenso de que a universidade atual vive, de fato, um processo de transformação em que a agenda e os resultados da sua pesquisa não se restringem mais, exclusivamente, às influências e demandas da esfera acadêmica.

No entanto, duas considerações se fazem importantes neste ponto. A primeira delas diz respeito aos diferentes tipos de universidade dentro de um mesmo sistema acadêmico e a outra, às diferenças comportamentais e normativas que podem ser encontradas dentro de uma mesma instituição no que se refere à comercialização da pesquisa acadêmica.

Quando o processo de transformação interna da universidade é tomado como objeto de análise, percebe-se pouco esforço da literatura em esclarecer que as diferenças entre os vários tipos de universidade (por exemplo: pública, privada, de ensino e pesquisa, exclusivamente de ensino, etc.) influenciam significativamente no modo e na intensidade como essa transformação acadêmica pode ocorrer.

No Brasil, a despeito de algumas exceções (uma ou outra universidade privada com tradição na condução da atividade de pesquisa e alguns centros de P\&D das empresas estatais), o desenvolvimento científico e tecnológico ocorreu (BRISOLLA, 1990) e continua ocorrendo, em grande medida, dentro das universidades públicas. Assim, qualquer análise sobre o processo de transformação da universidade deve levar em conta a natureza da instituição acadêmica e seu contexto político e institucional. 
Do ponto de vista interno, qualquer análise mais cuidadosa logo perceberá que a universidade não pode ser tratada como um "bloco monolítico", homogêneo e uníssono, sendo muito melhor caracterizada pelos aspectos da diversidade, da diferença e de suas nuances. Dessa forma, parece bastante provável que o olhar do observador encontre, dentro de uma mesma instituição acadêmica, significativas diferenças entre seus setores, institutos ou departamentos, no que se refere à proteção e comercialização da sua pesquisa.

Por fim, é importante esclarecer que, de modo geral, aceita-se aqui como válida a tese de que a universidade vive um processo de transformação (revolução) interna, muito embora não se tenha escolhido um modelo preferencial a ser seguido para a interpretação do fenômeno. A esse respeito sugerimos que a escolha de um ou outro modelo conceitual-analítico deverá estar condicionada ao contexto no qual a universidade se insere (localização, natureza e cultura institucional), assim como aos objetivos da análise.

\section{Transformação da universidade: oportunidade ou ameaça?}

Assumindo que o processo de transformação acadêmica está, de fato, em curso, nesta seção busca-se organizar os principais argumentos dos autores que veem essa transformação como benéfica, vantajosa para a universidade e daqueles que a consideram prejudicial, ameaçadora.

A percepção a respeito dessa polarização, contra ou a favor, não é necessariamente nova. Martin e Etzkowitz (2000), em um artigo a respeito da origem e evolução da universidade indicam haver duas teses contraditórias. De um lado haveria a tese "pessimista" 8 defendida por aqueles que acreditam que o futuro da universidade encontra-se ameaçado pela expectativa do governo e da sociedade de que a universidade deve executar atividades voltadas para resultados úteis, tais como produzir conhecimento aplicado que promova o desenvolvimento de habilidades mais úteis aos seus estudantes. Do lado oposto haveria a tese "otimista" que considera que nos movemos em direção à "sociedade baseada em conhecimento", ou também chamada "sociedade do conhecimento". Nessa segunda tese a universidade seria o motor da economia, ocupando um papel muito mais importante do que no passado.

Ainda refletindo sobre essa polarização Metlay (2006) afirma que, a despeito dos numerosos e talvez irreconciliáveis desacordos sobre o debate, ambos os lados indicam haver uma aguda distinção entre o que se considera ser a universidade atual e a universidade "tradicional".

${ }^{8}$ Martin e Etzkowitz (2000) utilizam o termo "declinist", aqui traduzido como pessimista. 


\section{0 discurso dos "pessimistas"}

Alternativamente, esta subseção poderia ter sido intitulada como "ameaça", considerando que nela se agrupam os principais argumentos em defesa da manutenção da natureza e do caráter da universidade tradicional, como rotulada por Metlay (2006).

0 primeiro argumento utilizado deste lado do debate refere-se ao processo de autonomia acadêmica. De acordo com alguns pesquisadores (ZIMAN, 1991; 1999), há o temor de que a pressão exercida sobre a universidade, para que ela tente responder aos anseios e necessidades da sociedade, comprometa os valores acadêmicos da autonomia, tanto da instituição quanto do seu pesquisador.

0 conceito de autonomia, citado por Ziman (1991; 1999), está claramente relacionado à norma do "desinteresse" de Merton (1970), segundo a qual os pesquisadores acadêmicos não deveriam definir sua agenda de pesquisa com base em "interesses externos" à ciência. Para os autores filiados ao pensamento Mertoniano, os interesses externos mutilam a ciência, devendo esta última ser orientada apenas a resolver problemas formulados pela própria ciência (POLANYI, 1962).

Esse conflito normativo também é apontado por Metlay (2006) quando afirma que os críticos ao processo de transformação da universidade exprimem certo desgosto pela perda de alguns valores acadêmicos tradicionais, tais como a liberdade acadêmica, a livre pesquisa e a ciência como vocação (pessoal e profissional).

No entanto, Ziman (1999) lembra que o crescimento da ciência acadêmica ao longo dos séculos resultou em um empreendimento vultoso e dispendioso, sendo ainda em grande medida financiado pelos governos nacionais. Consequentemente, os pesquisadores acadêmicos têm sido chamados a observar as necessidades sociais do ambiente onde vivem, o que acaba por se refletir diretamente na qualidade e no impacto dos resultados de suas pesquisas.

Dessa forma, Ziman (1999) também parece concordar com o argumento apresentado anteriormente de que a universidade vive um importante processo de mudança. Para o autor, a ciência atravessa um período de "revolução cultural", ou ainda, um movimento de ruptura da sua tradição acadêmica. Durante esse processo de mudança estaríamos testemunhando o surgimento de uma ciência "pós-acadêmica", que difere da ciência acadêmica tradicional em termos sociológicos e filosóficos, capaz de produzir um tipo diferente de conhecimento.

Um segundo argumento usado refere-se à combinação do processo de globalização, do desenvolvimento das novas tecnologias de informação e comunicação 
(TICs), e da mudança no padrão de consumo dos estudantes. Segundo Martin e Etzkowitz (2000), essa combinação de fatores promove a entrada indesejada de novos concorrentes no mercado da educação superior, incluindo entre os entrantes as universidades privadas ou empresas dedicadas ao ensino a distância.

Um terceiro argumento refere-se ao possivel enfraquecimento da relação entre as atividades de ensino e pesquisa. Segundo Martin e Etzkowitz (2000), as pressões externas (sociais) resultam em um maior número de alunos por sala em busca de um aumento da eficiência do processo de ensino, além da preocupação em oferecer as habilidades exigidas pela economia e pela sociedade, todas elas comprometendo a atividade de pesquisa. Do mesmo modo, as pressões para a condução das pesquisas e para o aumento das publicações podem resultar em uma redução da atenção dispensada à atividade de ensino.

Além disso, sem prejuízo ao argumento apresentado por Martin e Etzkowitz (2000), é possivel incluir a atividade de extensão na reflexão sobre divisão desejada entre as várias atividades acadêmicas em prol dos objetivos de produzir e disseminar o conhecimento científico à sociedade.

Ainda a respeito do tempo, vale observar a dedicação dos pesquisadores às atividades de proteção e comercialização dos seus inventos. De acordo com Lowe e Gonzalez-Brambila (2007) é possível que os acadêmicos envolvidos em pesquisas com potencial de exploração comercial dediquem uma parcela maior do seu tempo, dentro dos escritórios de transferência de tecnologia (ETT), administrando suas invenções protegidas, oferecendo consultorias, auxiliando no processo de licenciamento das suas patentes ou até mesmo criando uma pequena empresa, ao invés de conduzir suas atividades de ensino e pesquisa.

No que diz respeito à disseminação do conhecimento acadêmico à sociedade, alguns pesquisadores têm indicado a possibilidade de que haja redução no número de artigos publicados sobre pesquisas cujos resultados sejam passiveis de proteção por direitos de propriedade intelectual. Muito embora os resultados apresentados nos documentos de patente possam ser publicados imediatamente após o ato do depósito junto ao organismo competente, há o receio de que o tempo gasto para a publicação desses resultados aumente de modo a permitir que sejam conduzidos os trâmites do processo de proteção; ou ainda, que os pesquisadores desistam da publicação para manter alguma vantagem em busca da comercialização dos resultados da pesquisa (BLUMENTHAL et al., 1996; CAMPBELL et al., 2002). Esse comportamento levaria à violação da norma do comunalismo (MERTON, 1970), segundo a qual é obrigação precípua do pesquisador colocar seus resultados de pesquisa à disposição dos colegas através da publicação, para que possam ser criticados e usados para futuras pesquisas. 


\section{O discurso dos "otimistas"}

De modo similar à subseção anterior, esta poderia receber o título "oportunidade", considerando que aqui se agrupam os argumentos relacionados às oportunidades oferecidas à universidade enquanto agente central da produção de conhecimento na sociedade.

0 primeiro argumento destaca a crescente importância dos resultados da pesquisa acadêmica como fonte de novos conhecimentos para a economia, já que, em uma economia globalizada, a competitividade depende cada vez mais do processo de inovação baseado no conhecimento científico e tecnológico (MARTIN; ETZKOWITZ, 2000). Neste contexto, os adeptos ou defensores da transformação acadêmica argumentam que as universidades devem colocar o conhecimento para "trabalhar" (a favor da sociedade) e que as invenções acadêmicas devem ser estimuladas em todos os niveis, governamentais e industriais (METLAY, 2006).

Os defensores deste ponto de vista também costumam sinalizar para o fato de que a aproximação entre a empresa privada e a universidade, por meio da comercialização da pesquisa acadêmica, gera novas demandas e orientações para a pesquisa que se desenha dentro dos departamentos acadêmicos.

Outro argumento oferecido por Martin e Etzkowitz (2000), bastante próximo ao primeiro, refere-se ao crescimento da demanda por habilidades e aprendizagem contínua. Neste caso, as empresas, para se manterem atualizadas perante sua concorrência, buscarão na universidade programas de aperfeiçoamento contínuo que as permitam criar e adicionar valor aos seus produtos. Assim, da mesma forma que as TICs podem ser vistas como uma ameaça ao futuro da universidade atual, também podem ser consideradas como oportunidades quando permitem revolucionar os métodos de ensino e aprendizagem.

A esse conjunto sempre se adiciona a discussão do fluxo de recursos financeiros que se estabelecem a partir da cooperação universidade-empresa e da comercialização da pesquisa acadêmica. No entanto, a respeito dessa discussão cabem duas considerações importantes. A primeira delas, de caráter normativo e ideológico, sugere ser um equívoco imaginar que os recursos que eventualmente advenham da comercialização da pesquisa acadêmica possam substituir o papel do Estado como principal financiador da atividade acadêmica. A segunda consideração, mais pragmática, demonstra que, historicamente, o volume de recursos aplicados pelas empresas no ambiente acadêmico não se tem alterado significativamente e representa apenas uma pequena parcela do total (AUTM, 2005; NSB, 2006).

Apenas para citar o caso emblemático dos EUA, a pesquisa de avaliação conduzida anualmente pela Associação Norte-Americana de Gestores de Tecnolo- 
gia Universitária (Association of University Technology Managers - AUTM) indica que essa parcela tem-se mantido constante e próxima ao patamar de 7\% do total de gastos com a pesquisa conduzida pelas universidades, hospitais universitários e institutos de pesquisa norte-americanos, tendo alcançado em 2005 o montante aproximado de U\$3 bilhões (AUTM, 2005). Esses recursos financeiros, obtidos a partir da comercialização da pesquisa acadêmica, podem ser usados na manutenção e no investimento das atividades de pesquisa e ensino (LOWE; GONZALEZ-BRAMBILA, 2007).

Alguns autores (BLUMENTHAL et al., 1986a) apresentam evidências contrárias às críticas que surgem sobre o envolvimento do pesquisador acadêmico na relação com as empresas, e que costumam apontar o menor interesse e comprometimento desse pesquisador com as atividades acadêmicas tradicionais.

Em um estudo sobre a pesquisa cooperativa entre a universidade e a indústria, na área da biotecnologia ${ }^{9}$, Blumenthal e outros (1986b) indicam que os pesquisadores envolvidos e financiados pelas empresas apresentaram um desempenho acadêmico superior ao desempenho dos seus colegas que não haviam estabelecido vínculo com empresas, tendo tal desempenho sido medido em termos de publicações, patentes, participação em atividades profissionais e administrativas e rendimento financeiro. Complementarmente, os pesquisadores financiados pelas empresas relatam que suas pesquisas frequentemente resultam em segredos comerciais e que aspectos comerciais passam a ter algum impacto sobre suas escolhas sobre projetos de pesquisa.

Mais recentemente, Lowe e Gonzalez-Brambila (2007) indicam como um dos principais resultados da sua pesquisa que, na média, a produtividade acadêmica dos "pesquisadores empreendedores" 10 supera o nível alcançado pelos seus pares que não se envolveram na abertura de empresas.

No entanto, ainda que haja alguma tradição no estudo da produtividade do pesquisador acadêmico, recentemente tem havido um maior interesse em avaliar comparativamente as atividades científicas e comerciais conduzidas pela universidade.

Seguindo essa mesma motivação, a seção seguinte se propõe a discutir o uso das patentes como aspecto de análise de transformação na universidade, considerando os processos de proteção e comercialização da pesquisa acadêmica como seu principal vetor de mudança.

\footnotetext{
${ }^{9}$ Os autores (BLUMENTHAL et al., 1986b) utilizam a expressão "University-Industry Research Relationships (UIRR's)" para identificar a cooperação em pesquisa biotecnológica estabelecida a partir do início dos anos 80 entre empresas e universidades norte-americanas.

${ }^{10}$ Os autores usam a expressão "faculty entrepreneurs" para identificar a amostra dos 150 pesquisadores entrevistados. Em todos os casos eles permanecem contratados pelas universidades em regime de dedicação exclusiva e, paralelamente, haviam fundado empresas entre os anos de 1990 e 1999.
} 


\section{As patentes universitárias como um aspecto de análise da transformação acadêmica}

Conforme mencionado anteriormente, embora as transformações acadêmicas possam ser observadas por meio de inúmeros aspectos, tais como a criação de spin-offs acadêmicos ${ }^{11}$, a condução de projetos de pesquisa e desenvolvimento (P\&D) em cooperação entre universidade e empresa, ou ainda pela execução de atividades mais simples como as prestações de serviço (assessorias, consultorias, ensaios, testes e emissão de laudos técnicos), o processo de transferência de tecnologia pelo licenciamento de patentes vem apresentando um comportamento crescente ao longo dos últimos anos.

De acordo com Metlay (2006), alguns autores não adotam uma postura explícita sobre a posição da universidade moderna [de pesquisa], mas implicitamente reforçam o sentido de "renovação" quando focam sua atenção exclusivamente sobre as universidades da era do Ato Bayh-Dole ${ }^{12}$. 0 autor indica que embora vários pesquisadores (MCCRAY; CROISSANT, 2001; KAGHAN, 2001; FELLER, 1990) tenham utilizado outras abordagens e objetos de pesquisa para apresentar suas opiniões sobre o debate, todos eles reconhecem a importância do Ato Bayh-Dole como sendo a legislação que permitiu às universidades dos EUA assegurarem com maior facilidade os direitos de propriedade intelectual obtidos com recursos federais.

Especificamente no caso dos EUA, o aumento dos indicadores de patenteamento e licenciamento acadêmico tem sido frequentemente interpretado como resultado direto da política governamental norte-americana (Ato Bayh-Dole).

De acordo com os dados da Associação dos Gestores de Tecnologia das Universidades (AUTM), embora tenha havido uma pequena queda entre $2004 \mathrm{e}$ 2005, quando se considera um período mais amplo, identifica-se claramente 0 crescimento no número de novos documentos depositados pelas universidades, hospitais universitários e institutos de pesquisa norte-americanos junto ao Escritório Americano de Marcas e Patentes (United States Patent and Trademark Office - USPTO), tendo passado de 6.073 em 2000 para 10.270 em 2005, conforme pode ser observado na tabela 1.

\footnotetext{
"Brisolla (1998a, p. 83) descreve de forma bastante clara o significado de spin-off acadêmico como "um processo no qual pesquisadores acadêmicos, geralmente como fruto de uma atividade de pesquisa que lhes parece promissora do ponto de vista prático, aventuram-se a assumir o papel de empresário ou associam-se a empresários interessados em assumir o risco de transformar sua idéia ou o resultado de sua pesquisa em produto. Geralmente isso é acompanhado pelo afastamento do cientista das universidades de origem ou pela redução de sua dedicação ao trabalho acadêmico."

${ }^{12}$ Vigente desde 12 de dezembro de 1980, o Ato Bayh-Dole é reconhecido como um marco na política norte- americana de estímulo à proteção e comercialização de tecnologias. De acordo com o Ato, as pequenas empresas e as organizações sem fins lucrativos, incluindo as universidades, passaram a ser titulares (proprietárias) das invenções obtidas a partir dos resultados dos programas de pesquisa financiados com recursos governamentais.
} 
Tabela 1 - Novos documentos de patente depositados por universidades, hospitais universitários e institutos de pesquisa norte-americanos junto ao USPTO, 2000 a 2005.

\begin{tabular}{l|r|r|r|r|r|r}
\hline & 2000 & 2001 & 2002 & 2003 & 2004 & 2005 \\
\hline Instituições que responderam à pesquisa & 167 & 170 & 189 & 198 & 192 & 191 \\
\hline Novos documentos depositados no USPTO & 6.073 & 6.397 & 7.319 & 7.921 & 10.517 & 10.270 \\
\hline Total de documentos depositados no USPTO & 9.557 & 10.687 & 12.222 & 13.280 & 13.803 & 14.757 \\
\hline Documentos concedidos pelo USPTO & 3.567 & 3.559 & 3.501 & 3.933 & 3.680 & 3.278 \\
\hline
\end{tabular}

Fonte: AUTM U.S. Licensing Survey, FY 2005 (AUTM, 2005).

No entanto, a mesma tabela 1 mostra que o número total de patentes concedidas às universidades norte-americanas por ano permanece relativamente estável ao longo do período entre 2000 e 2005.

Dentre as inúmeras hipóteses que podem ser associadas à tentativa de explicar a diferença entre o número de depósitos e concessões às universidades dos EUA, ao menos quatro são abordadas neste momento. Ainda que isoladamente tenham suas limitações, em conjunto oferecem uma proposta de análise consistente para o meIhor entendimento dessa disparidade.

Uma das hipóteses a ser verificada relaciona-se à capacidade operativa do USPTO em analisar os pedidos de patente depositados. De acordo com o USPTO (2007), o prazo médio gasto entre o depósito e a concessão de uma patente é de aproximadamente de 24 meses. No entanto, esse prazo depende de inúmeros fatores tais como a carga de trabalho (que varia entre as inúmeras tecnologias), o orçamento, 0 contingente humano operacional ${ }^{13}$ e o plano de impressão de patentes, dentre ou$\operatorname{tros}^{14}$. Dessa forma, vale observar se há alguma tendência de aumento no referido prazo de modo a interferir significativamente sobre a diferença entre o número de patentes depositadas e concedidas pelo USPTO.

Outra hipótese a ser verificada refere-se à qualidade das patentes submetidas para análise do USPTO. Vale lembrar que para um documento de patente ser concedido pela autoridade examinadora, os três requisitos de patenteabilidade ${ }^{15}$ devem ser simultaneamente atingidos. Uma eventual corrida das universidades em busca de um "melhor" indicador de sua propriedade intelectual pode levar ao aumento do número de depósitos sem o correspondente aumento no número de concessões. Um ponto de partida para verificar esta hipótese seria observar a evolução dos pedidos de universidades dos EUA indeferidos pelo USPTO.

\footnotetext{
${ }^{13}$ De acordo com Amorim-Borher e outros (2007), por conta do crescente aumento dos depósitos de marcas e patentes nos EUA, o USPTO tem como meta a incorporação funcional de pelo menos 1.000 novos examinadores ao ano.

${ }^{14} \mathrm{O}$ USPTO (2007) indica que em 1986 concedeu um número de patentes menor do que era esperado devido à falta de orçamento para a impressão de documentos de patente.

${ }^{15}$ Apenas para lembrar, são eles: novidade, atividade inventiva e aplicação industrial.
} 
Uma terceira hipótese remete à possibilidade de que o número de universidades depositantes tenha crescido nos últimos anos, elevando assim o número total de depósitos realizados pelas universidades. Infelizmente, o número de depósitos realizados pelas universidades dos EUA não se encontra compilado no sítio eletrônico do USPTO, o que pode significar um esforço adicional para a validação desta hipótese.

Da hipótese anterior decorre o fato de que o número de novas universidades criadas nos EUA não seria suficiente para explicar o crescimento no número de depósitos de patentes acadêmicas. Dessa forma, parece ser mais razoável considerar como válida a hipótese de que o aumento no número de depósitos de patentes acadêmicas esteja diretamente vinculado às universidades que não tinham tradição em proteger suas tecnologias em períodos anteriores, e que podem ter sido estimuladas nos anos mais recentes pelo comportamento das universidades líderes e pela politica governamental norte-americana (Ato Bayh-Dole).

Embora a importância do Ato Bayh-Dole seja amplamente citada pela literatura, seus efeitos sobre as universidades e sobre o sistema de inovação dos EUA não têm sido objeto direto da pesquisa empírica (MOWERY et al., 2001; MOWERY; ZIEDONIS, 2002; SAMPAT; MOWERY, ZIEDONIS, 2003).

Nesse sentido, Geuna e Nesta (2004), apresentam uma análise preliminar do processo de patenteamento na universidade e seus efeitos sobre a pesquisa acadêmica, explorando as possiveis consequências do aumento do processo de patenteamento nas universidades européias sobre a pesquisa acadêmica conduzida nessas mesmas universidades.

Embora reconheçam que os direitos de propriedade intelectual (PI), dentro dos quais estão as patentes, podem ter impactos positivos quando explorados pelas universidades, Geuna e Nesta $(2004 ; 2006)$ indicam que a maior parte da literatura se refere a essas vantagens sem levar em conta os custos ou riscos envolvidos nessas atividades. Além disso, segundo eles, as mesmas vantagens são apresentadas sem qualquer evidência empírica com suporte estatístico e, por isso, podem ser consideradas apenas como hipóteses.

No entanto, Geuna e Nesta (2006) afirmam ser extremamente dificil avaliar o impacto do aumento do envolvimento institucional em propriedade intelectual (PI) sobre a pesquisa acadêmica pelo fato de que a titularidade (propriedade) e o licenciamento dos inventos são apenas uma parte do conjunto das novas ferramentas de transferência de tecnologia que têm sido desenvolvidas pelas universidades ao longo dos últimos 20 anos.

Isso significa dizer que há um amplo conjunto de atividades de transferência de tecnologia que podem afetar a forma na qual a pesquisa acadêmica é conduzida, sendo todas elas consideradas como potenciais fatores de interação que podem influenciar o comportamento dos pesquisadores acadêmicos. 
A partir dessa consideração, Geuna e Nesta (2006) apresentam uma lista de aspectos a serem observados no sentido de tentar verificar alguma mudança no comportamento do pesquisador acadêmico após o seu envolvimento com as atividades de propriedade intelectual (PI), sendo eles:

- o tempo dedicado pelo pesquisador à atividade de ensino;

- a escolha das fontes de financiamento (governo, setor privado, outros), considerando que as universidades têm sido chamadas a diversificar suas fontes de financiamento;

- a definição dos objetivos de pesquisa (orientada pelo problema científico ou orientada pela indústria);

- a complementação financeira e a mudança no status do pesquisador (forma de vínculo). Recentes alterações na legislação de diversos paises têm produzido mudanças nas estruturas de incentivo e recompensa dentro das universidades. Atualmente, em vários paises na União Européia, os pesquisadores podem receber uma parte dos royalties derivados das suas patentes, embora a patente pertença legalmente à instituição na qual o invento foi desenvolvido.

A respeito desse último aspecto listado, os autores afirmam que os pesquisadores acadêmicos têm sido incentivados a complementar suas atividades de pesquisa com atividades de transferência de tecnologia. Na França, os pesquisadores já podem usar parte do seu tempo para atividades cooperativas com a indústria.

Uma reflexão adicional a respeito dos impactos do processo de proteção e comercialização dos resultados da pesquisa acadêmica sobre o comportamento do cientista, deve considerar os seguintes aspectos:

- o uso sistemático das bases de documentos de patente pode reorientar as escolhas dos problemas e temas de pesquisa, redefinindo a agenda de pesquisa;

- a definição do grupo de pesquisadores, concretizada pela escolha dos perfis dos alunos de graduação e pós-graduação que conduzirão os projetos de pesquisa;

- na definição das alianças e estratégias, por meio da escoIha de quais grupos de pesquisa (públicos, privados ou mistos) serão definidos como parceiros na condução das pesquisas; e

- o desempenho acadêmico, medido em termos do volume e do fator de impacto das publicações em periódicos indexados, de modo similar ao trabalho conduzido por Blumental e outros (1986). 
Embora os resultados obtidos para o caso europeu apresentem particularidades que não possam ser observadas no Brasil, a abordagem de análise comparativa pode-se mostrar especialmente interessante, como no caso da maioria dos paises latino-americanos, o desenvolvimento científico e tecnológico brasileiro concentrou-se nas universidades públicas ${ }^{16}$, em alguns institutos de pesquisa e nos centros de P\&D da empresas estatais.

De acordo com Fujino e Stal (2004) a cultura organizacional das universidades públicas brasileiras vem sendo sustentada, de um lado, por ideologias que defendem o livre acesso aos resultados da pesquisa acadêmica desenvolvida com recursos públicos e, de outro lado, por normas que mantêm a hierarquia administrativa burocrática pela instituição.

Entretanto, mais recentemente, a visão a respeito da apropriação econômica dos resultados das pesquisas acadêmicas, pela própria universidade, tem recebido maior atenção, principalmente no discurso e na ação política dos gestores dos Núcleos de Inovação Tecnológica ${ }^{17}$, alguns recentemente criados nas Instituições Científicas e Tecnológicas (ICTs), dentre as quais estão as universidades públicas. Consequentemente, já é possivel notar uma maior movimentação dessas universidades em busca de estabelecerem mecanismos internos formais que garantam a proteção e a comercialização das suas tecnologias, principalmente por meio do depósito e licenciamento de patentes.

$\mathrm{Na}$ verdade, apenas recentemente o caminho tecnológico trilhado pelas ICTs brasileiras recebeu seu primeiro "pavimento" normativo ${ }^{18}$. No Brasil, assim como em outros paises, o quadro normativo atual também prevê a apropriação direta dos resultados da pesquisa acadêmica pelas próprias ICTs e indireta pelos seus pesquisadores.

Consequentemente, o peso das universidades e instituições de pesquisa no esforço total de patenteamento no Brasil tem sido significativo. De acordo com a última versão dos "Indicadores Fapesp 2004" (LANDI; GUSMÃO, 2005), quatro universidades ou institutos de pesquisa figuram entre as 20 instituições que lideram 0 movimento de patenteamento no Brasil.

\section{Considerações finais}

Ainda que a Política de Ciência e Tecnologia, nos seus vários níveis, estimule a atividade de proteção e comercialização da pesquisa acadêmica, não estão previstos mecanismos que reflitam uma preocupação concreta com o monitoramento dos impactos deste processo na universidade.

\footnotetext{
${ }^{16} 0$ sistema de ensino superior europeu também é, via-de-regra, baseado em instituições públicas.

${ }^{17}$ Embora esta seja a denominação usada pela Lei de Inovação, Lei n 10.973 (BRASIL, 2004) e Decreto $n^{\circ} 5.563$ (BRASIL, 2005), expressões como Agência e Escritório também podem ser encontradas nas instituições acadêmicas.

${ }^{18}$ Lei $n^{\circ} 10.973$ (BRASIL, 2004) e Decreto $n^{\circ} 5.563$ (BRASIL, 2005).
} 
Considerando a falta de evidência empírica a respeito do impacto da proteção e comercialização da pesquisa acadêmica sobre as demais atividades conduzidas pela universidade, torna-se premente dedicar algum esforço analítico que contribua para o melhor entendimento dos riscos e benefícios associados a esse processo.

A universidade, como parte interessada na manutenção desses benefícios e na minimização dos riscos, deve manter-se atenta aos seus processos de transformação interna, principalmente em relação àqueles que produzem efeitos diretamente sobre os seus objetivos.

Nesse sentido, sem que haja a pretensão de esgotar as inúmeras possibilidades de estudos que ajudem a identificar e elucidar tais efeitos, ao menos duas abordagens decorrem da discussão apresentada neste trabalho.

Uma delas passa pela proposta de analisar o comportamento dos cientistas enquanto atores sociais envolvidos no processo de proteção e comercialização dos resultados da pesquisa acadêmica, em busca de contribuições consistentes para 0 campo da Sociologia da Ciência. Aspectos específicos tais como a definição da agenda de pesquisa; a escolha das fontes de financiamento, das fontes de pesquisa bibliográfica e dos meios de publicação; a questão do tempo de dedicação às inúmeras atividades acadêmicas; a escolha do perfil dos alunos de pós-graduação; a escolha de quais grupos de pesquisa participar ou quais grupos formar, a solução individual do "dilema" publicar versus patentear, o sistema de incentivo e de desempenho acadêmico, dentre outros, podem ser objetos de estudos isolados ou associados, dependendo do enfoque específico a ser dado ao estudo.

Outra abordagem possivel decorre das recentes mudanças na política científica e tecnológica brasileira, especialmente a partir da vigência da Lei de Inovação e seu decreto regulamentador. Ainda se encontra em andamento o processo de adaptação e adequação legal, politica e organizacional dentro das ICTs brasileiras. Nesse contexto, surgem possibilidades concretas para os estudos no campo da Análise de Política, com o objetivo de melhor entender o processo de elaboração da política de proteção e comercialização da pesquisa acadêmica em seu conjunto, tanto na dimensão do processo de tomada de decisão pelos atores intervenientes como na identificação de falhas de implementação em relação à formulação dessas políticas. Aspectos envolvidos no processo de conformação da agenda de decisão tais como: conflitos latentes, conflitos encobertos, mecanismos ideológicos e relações de poder estabelecidas entre os agentes são especialmente interessantes para ajudar a entender os modelos cognitivos usados pela comunidade acadêmica na formulação de suas políticas internas.

Estudos e análises nas direções aqui sugeridas poderiam contribuir muito para o acompanhamento e avaliação das universidades brasileiras e para a elaboração de políticas de Ciência e Tecnologia e de Educação Superior. 


\section{Referências}

AMORIM-BORHER, M. B. et al. Ensino e pesquisa em propriedade intelectual no Brasil. Revista Brasileira de Inovação, Rio de Janeiro, v. 6, p. 281-310, jul./dez. 2007.

ASSOCIATION OF UNIVERSITY TECHNOLOGY MANAGERS. A survey summary of technology licensing (and related) performance for U.S. Academic and Nonprofit Institutions and Technology Investment Firms. Chicago, 2005. Disponível em: <http://www.autm.net/events/File/US_LS_05Final(1).pdf>. Acesso em: 18 jun. 2007.

BLUMENTHAL, D. et al. Evidence from a National Survey of Faculty. Journal of The American Medical Association, Chicago, IL, v. 277, p. 1224-1228, 1996.

BLUMENTHAL, D. et al. Industrial support of University Research in Biotechnology. Science, Danvers, MA, v. 231, p. 242-246, 1986 a.

BLUMENTHAL, D. et al. University-Industry Research Relationships in Biotechnology: implications for the university. Science, Danvers, MA, v. 232, p. 1361-1366, 1986 b.

BRASIL. Decreto n 5.563, de 11 de outubro de 2005. Regulamenta a Lei $\mathrm{n}^{0}$ 10.973, de 2 de dezembro de 2004, que dispõe sobre incentivos à inovação e à pesquisa científica e tecnológica no ambiente produtivo, e dá outras providências. Diário Oficial [da República Federativa do Brasil], Brasília, DF, 13 out. 2005.

. Lei no 10.973, de 2 de dezembro de 2004. Dispõe sobre incentivos à inovação e à pesquisa científica e tecnológica no ambiente produtivo, e dá outras providências. Diário Oficial [da República Federativa do Brasil], Brasília, DF, 3 dez. 2004.

Ministério da Ciência e Tecnologia. Conselho Nacional de

Desenvolvimento Científico e Tecnológico. Relatório. Brasília, DF, 2001. Disponível em: <http://www.cnpq.br/cnpq/relatorio.htm>. Acesso em: 23 mar. 2007.

BRISOLLA, S. N. A relação da universidade co o setor produtivo: o caso da UNICAMP. Revista de Administração da USP, São Paulo, v. 25, n. 1, p. 106-126, jan./mar. 1990.

Relação universidade-empresa: como seria se fosse. In: FERREIRA, José Rincón (Org.). Interação universidade-empresa. Brasília, DF: IBICT: CNPQ: Instituto Euvaldo Lodi, 1998a.

(Coord.) Relatório final: o papel da universidade na pesquisa aplicada e na formação de profissionais: um estudo de caso da Unicamp. Campinas, SP: Universidade Estadual de Campinas, 1998 b. 
CAMPBELL, E. G. et al. Data withholding in academic genetics. Journal of The American Medical Association, Chicago, IL, v. 287, p. 473-480, 2002.

CHARLES, D.; CONWAY, C. A report by the Centre for Urban and Regional Development Studies: University of Newcastle upon Tyne. Higher Education-Business Interaction Survey, Bristol, 2001. Research report 01/68. Disponivel em: <http:// www.hefce.ac.uk/Pubs/hefce/2001/01_68.htm\#exec.>. Acesso em: 17 mar. 2008.

DAGNINO, R. A relação universidade-empresa no Brasil e o "argumento da Hélice Tripla". Revista Brasileira de Inovação, Rio de Janeiro, v. 2, p. 267-308, 2003.

DAVID, P. A.; HALL, B. H. Property and the pursuit of knowledge: IPR issues affecting scientific research: introduction. Research Policy, Amsterdam, v. 35, p. 767-771, 2006.

ETZKOWITZ, H. The norms of entrepreneurial science: cognitive effects of the new university-industry linkage. Research Policy, Amsterdam, v. 27, p. 823-833, 1998.

ETZKOWITZ, H. ; LEYDESDORFF, L. The dynamics of innovation: from National Systems and "Mode 2" to a Triple Helix of university-industry-government relations. Research Policy, Amsterdam, v. 29, p. 109-123, 2000.

The Triple Helix: university-industry-government relations: a laboratory for knowledge based economic development, Amsterdam. In: THEME PAPER: Workshop Amsterdam, 1., 1995, Amsterdam. Proceedings... Amsterdam, 1996.

ETZKOWITZ, H.; WEBSTER, A. Science as intellectual property. Science and technology studies handbook. London: Sage Publications, 1994.

FELLER, I. University patent and technology-licensing strategies. Educational Policy, Thousand Oaks, CA, v. 4, p. 327-340, 1990.

FUJINO, A.; STAL, E. Gestão da propriedade intelectual na universidade pública brasileira: diretrizes para licenciamento e comercialização. In: SIMPÓSIO DE GESTÃO E INOVAÇÃO TECNOLÓGICA, 23., 2004, Curitiba. Anais... São Paulo: USP/PGT, 2004.

GEUNA, A.; NESTA, J. J. L. University patenting and its effects on academic research. Brighton: University of Sussex, 2004. SPRU Electronic Working Paper Series 99. Disponivel em: <http://www.sussex.ac.uk/Units/spru/publications/ imprint/sewps/sewp99/sewp99.pdf.>. Acesso em: 15 jun. 2005. 
. University patenting and its effects on academic research: the emerging European evidence. Research Policy, Amsterdam, v. 35, p. 790-807, July 2006.

GIBBONS, M. et al. The new production of knowledge: the dynamics of science and research in contemporary societies. Newbury Park, CA: Sage, 1994.

KAGHAN, W. Harnessing a public conglomerate: professional technology transfer management and the entrepreneurial university. In: CROISSANT, J.; RESTIVO, S. (Ed.). Degrees of compromise. New York : SUNY Press, 2001.

KLINE, S.; ROSENBERG, N. An overview of innovation. In: LANDAU, R.; ROSENBERG, N. (Ed.). The positive sum strategy. Washington, DC: National Academy of Press, 1986.

LANDI, F. R.; GUSMÃO, R. (Coord.). Indicadores de ciência, tecnologia e inovação em São Paulo 2004. São Paulo: FAPESP, 2005.

LOWE, R. A.; GONZALEZ-BRAMBILA, C. Faculty entrepreneurs and research productivity. The Journal of Technology Transfer, Amsterdam, v. 32, p. 173-194, 2007.

MCCRAY, W. P.; CROISSANT, J., Entrepreneurship in technology transfer offices: making work possible. In: CROISSANT, J.; RESTIVO, S. (Ed.). Degrees of compromise. New York: SUNY Press, 2001.

MARTIN, B. R. The changing social contract for science and the evolution of the university. In: GEUNA, A. et al. (Coord). Science and innovation: rethinking the rationales for funding and governance. Cheltenham, UK: Northamptom, USA : Edward Elgar, 2003.

MARTIN, B. R.; ETZKOWITZ, H. The origin and evolution of the university species. Vest, New Haven, v. 31, p. 9-34, 2000.

MERTON, R. K. Sociologia: teoria e estrutura. São Paulo: Mestre Jou, 1970.

METLAY, G. Reconsidering renormalization: stability and change in 20th-century views on university patents. Social Studies of Science, Thousand Oaks, CA, v. 36, p. 565-597, 2006.

MOWERY, D. C. et al. The growth of patenting and licensing by U.S. universities: an assessment of the effects of the Bayh-Dole act of 1980. Research Policy, Amsterdam, v. 30, p. 99-119, 2001. 
MOWERY, D. C.; ZIEDONIS, A. A. Academic patent quality and quantity before and after the Bayh-Dole act in the United States, Research Policy, Amsterdam, v. 31, p. 399-418, 2002.

MULKAY, M. J. Science and the sociology of knowledge. London: George Allen \& Unwin Publishers Ltd, 1979.

NATIONAL AUDIT OFFICE. Delivering the commercialization of public sector science: report by the comptroller and auditor general. London : HMSO, 2002.

NATIONAL SCIENCE BOARD. Science and engineering indicators 2006. Arlington, VA, 2006. Disponivel em: <http://www.nsf.gov/statistics/seind06/>. Acesso em: 25 jun. 2007.

NELKIN, D. Science as intellectual property: who controls research?. New York: Macmillan Publishing Company, 1984. (AAAS series on issues in science and technology).

NELSEN, L. The rise of intellectual property protection in the American University. Science, Danvers, MA, v. 279, p. 1460-1461, 1998.

NELSON, R. R.; ROSENBERG, N. Technical innovation and national systems. In: NELSON, R. R., (Ed.). National Innovation Systems: a comparative analysis. New York: Oxford University Press, 1993.

OECD. Draft final report on the strategic use of intellectual property by public research organizations. Paris, 2002.

OLIVEIRA, R. M. A cooperação da Universidade Federal de São Carlos com a sociedade. São Carlos, 2002. 158 p. Dissertação (Mestrado) - Departamento de Engenharia de Produção, Universidade Federal de São Carlos, São Carlos, 2002.

PETERS, L. S. Academic crossroads: the U.S. experience. New York: RPI: Center For Technology Policy, Oct. 1987.

PLONSKI, G. A. Cooperação universidade-empresa na Ibero-América: estágio atual e perspectivas. Revista de Administração, São Paulo, v. 30, n.2, p. 65-74, abr./jun. 1995.

SÁBATO, J.; BOTANA, N. La ciencia y la tecnologia en el desarrollo future de America Latina. In: THE WORLD ORDER MODELS CONFERENCE, 1968, Bellagio. Proceedings... Bellagio, Italy, 1968. Disponivel em: <http://cecae.usp.br/tecla/ html/pg_info_arti1.html/>. Acesso em: 20 mar. 2009. 
SAMPAT, B. N.; MOWERY, D. C.; ZIEDONIS, A. A. Changes in university patent quality after the Bayh-Dole act: a re-examination. International Journal of Industrial Organization, Amsterdam, v. 21, p. 1371-1390, 2003.

SLAUGTHER, S. The "trafic" in graduate students: graduate students as tokens of exchange between academe and industry. Science Technology Human Values, Thousand Oaks, CA, v. 27, p. 282-312, 2002.

SUTZ, J. The university-industry-government relations in Latin America. Research Policy, Amsterdam, v. 29, p. 279-290, 2000.

UNITED STATES PATENT AND TRADEMARK OFFICE. U.S. colleges and universities-utility patent grants, calendar years 1969-2005: patents distributed by calendar year of patent application - Explanation of Data. Alexandria, VA, 2007. Disponivel em: <http://www.uspto.gov/web/offices/ac/ido/oeip/taf/univ/ org_fi/explan.htm>. Acesso em: 12 abr. 2008.

VELHO, L. Ciências, publicações e avaliação. In: HOFFMANN, W. A. M.; FURNIVAL, A. C. (Org.). Olhar: ciência, tecnologia e sociedade. São Carlos: Pedro e João Editores; CECH-UFSCar, p. 9-21, 2008.

WEBSTER, A. J. Institutional stability: engineering an environment for biotechnology. Science and Public Policy, Cambridge, MA, v. 17, n. 5, Dec. 1990.

WEBSTER, A. J.; ETZKOWITZ H. Academic-Industry relations: the second academic revolution. London: Science Policy Support Group, 1991. SPSG concept paper n. 12.

ZIMAN, J. Academic science as a system of markets. Higher Education Quarterly, London, n. 12, p. 57-68, 1991.

A ciência da sociedade moderna. In: GIL, F. (Coord.). A ciência tal qual se faz. Coleção Humanismo e Ciência. Lisboa: Edições João Sá da Costa, 1999.

Prometheus bound: science in a dynamic steady state. Cambridge: Cambridge University Press, 1994.

Recebido em: 16/10/2008

Aceito para publicação em: 11/02/2009 